\title{
El proceso político y el desarrollo económico de México*
}

\author{
Fernando Rosenzweig Hernández
}

El enfoque del proceso político desde el punto de vista de sus relaciones con el desarrollo de la economia, a fin de poder discernir influencias mutuas, explorar desajustes y definir posibilidades de más adecuada armonización e integración, constituye una de las cuestiones fundamentales que hoy están planteadas en México y en otros países que aspiran a desenvolverse de una manera más rápida, eficiente y equilibrada. En la presente exposición me propongo intentar ese enfoque para el caso de mi país, buscando elementos de juicio para poder responder a la pregunta siguiente: ¿hasta qué punto puede considerarse que existe un desajuste entre la actual estructura social y política mexicana y las exigencias del crecimiento económico, y en la medida en que lo haya, qué podría ensayarse para lograr su corrección?

Sé muy bien que estoy internándome en un terreno cuyas primeras exploraciones son todavía recientes, y en el cual sólo un tratamiento complejo, con los recursos combinados de varias disciplinas científicas, puede conducirnos a recoger frutos positivos. Me alienta, sin embargo, a esta incursión la experiencia que he acumulado por mi participación en diversos trabajos sobre el desarrollo económico y la historia económica de mi pais. En realidad, el investigador que aspira a entender los problemas de la historia y el desarrollo de la economia, no puede prescindir de formarse un juicio sobre el significado que en estos órdenes alcanzan las estructuras políticas y sociales y su funcionamiento. Quisiera decir algo sobre la formación de esos juicios de carácter social y político de que se vale el economista para integrar el contexto a la luz del cual habrá de examinarse un fenómeno. De ninguna manera sería admisible, para principiar, que el economista invadiera por su cuenta y riesgo los campos de la ciencia política y la sociología, cuando incluso en el suyo propio existen todavía tantas zonas confusas que reclaman su esfuerzo. Sin embargo, el seguimiento de una pista puede obligar a conducir el análisis hasta los linderos con otros territorios del saber, a prolongarlo cuando menos hasta puntos de contacto con otras especialidades afines que luego, ya en sus propias jurisdicciones, se ocuparian de proseguir el estudio. Pero es viable que la franja colindante se encuentre todavía subdesarrollada, y que resulte necesario, al ubicar en ella un problema, en un cruzamiento de interrelaciones e interinfluencias, quebrantar las frágiles e indeterminadas líneas de demarcación entre las disciplinas. Esto no debe alarmar a nadie. En la historia del saber humano, este tipo de incursiones fronterizas jamás, que yo sepa, ha ocasionado conflictos, y si se deben a ellas estímulos eficientes para el avance de las diversas ciencias vecinas. A reserva de que se constituya en su oportunidad una comisión de límites, los economistas, los soció-

* Publicado en El Trimestre Económico, México, FCE, Oct.-Dic. 1962, vol. XXIX, núm. 116, p. 513-530. 
logos y los especialistas en ciencia política, cuando menos, deberían considerarse en un estado de reto deportivo, para ver quiénes logran realizar incursiones más repetidas y fructíferas en esas fronteras no conquistadas.

Por otra parte, las concepciones políticas y sociales de que no puede menos que echar mano el economista para lograr construir los planteamientos operativos que le hacen falta, pueden haberse llegado a configurar de una manera implícita, y hasta tal vez inconsciente, al actuar sobre su campo principal de trabajo, y presentársele la necesidad de mirarlo en perspectiva respecto a campos adyacentes. Esas concepciones se apoyarán, quizá, en hipótesis más o menos elaboradas, bosquejos de ideas más o menos bien definidas, o simplemente juicios prestados por otras disciplinas y hasta, tal vez, prejuicios emanados del vulgo. Pocas veces, si es que alguna, surge la ocasión, o se percibe la necesidad de emprender una revisión más sistemática, de tal suerte que el caudal de conocimientos se depure e integre en una armazón más sólida, y la inteligencia acuda a colmar lagunas antes encubiertas. Desde luego, no es posible prescindir, en el estudio de los fenómenos económicos, de puntos de referencia claros y bien fundados sobre el cuadro de circunstancias sociales y políticas en que aquéllos se manifiestan, en parte como condicionantes y en parte condicionados. Es obvia, pues, la utilidad de rescatar la imagen de esos puntos de referencia del mundo de lo tácito, que puede llegar hasta lo confuso y lo anticientífico, y darle un trazo esmerado y seguro. Hay que hacer esto ya se trate de abordar la historia económica o, sobre todo, el desarrollo económico.

Me referiré primero al desarrollo. Este se nos presenta como la posibilidad de materializar vastos cambios en la estructura de la economía y en la forma de crecimiento de sus diversos agregados, con el fin de imbuirle un sentido dinámico y orientarla hacia una integración eficiente. Un contenido de valores sociales a cuidar y enriquecer acompaña y explica al designio de lograr el desarrollo económico; se aspira a fortalecer o forjar las bases en que la sociedad sea capaz de sustentar mejores nivèles de bienestar material, términos de convivencia armoniosa entre sus partes componentes, y perspectivas de una vida espiritual fecunda. Bajo esta luz, el desarrollo económico es condición del desarrollo social, sin olvidar por supuesto que al cobrar éste un impetu adecuado se convierte a su vez en una fuerza que impulsa al primero. La modernización de la estructura política resulta, por su parte, un reflejo de los avances que logran las estructuras económicas y sociales, pues de ellas dependen, pero a su vez el desarrollo político ejerce una influencia considerable que puede acelerar o retardar el ritmo del avance económico y social.

Por lo general, la secuencia de los cambios que acarrea el desarrollo parece iniciarse en el campo de los fenómenos económicos, tal vez por virtud de nuevos descubrimientos de recursos, de inmigraciones humanas, de la gradual integración de mercados locales o regionales en ámbitos más amplios, de fuerzas de la demanda externa y; en una palabra, de circunstancias propicias a la formación de capitales, internos o procedentes del exterior, y en su sentido más amplio, a manifestaciones acumulativas de crecimiento que, en un momento dado, comienzan a asomar. Parece también que una vez comenzados, los cambios económicos tienden a provocar el remodelamiento de la estructura social, en su composición por estratos, de tal suerte que unas capas, lo mismo en la cúspide que en la base de la pirámide social, se van debilitando y aca- 
ban por caducar, si su base de sustentación radica en las estructuras económicas puestas en crisis por el desarrollo, en tanto que otras capas crecen y tienden a predominar, pues se desplazan sobre la cresta de la ola innovadora. La estructura vieja cede gradualmente, o bien sólo cede trastocada por un sacudimiento revolucionario. Finalmente, las estructuras del poder político se desplazan hacia un nuevo centro de gravedad.

Ahora bien, una sociedad que se encuentra en los umbrales del desarrollo, o cuyo desarrollo sea sólo incipiente, puede quedar atrapada en un círculo vicioso. Y esto por la razón de que el desenvolvimiento de la economía tropiece con obstáculos que únicamente la acción del Estado podría remover, y que éste en realidad mantiene o hace mayores por ser, él mismo, un reflejo del contexto de circunstancias que caducarian con el desarrollo. Esta anormalidad, tantas veces ejemplificada en la historia, consistente en que las estructuras sociales y políticas, apuntaladas en ocasiones desde el extranjero, mantengan a raya a la estructura económica, comprimida en una fase estacionaria o aun regresiva, y le cierren el camino al progreso humano, constituye uno de los problemas más serios y más hondos que tenemos enfrente los hombres del siglo XX. Hemos llegado a una encrucijada - y no me detendré a explicar las harto conocidas razones de ello - en que el desarrollo económico sólo es asequible mediante una política económica que se lo proponga. Pensar en el desarrollo económico es inseparable de pensar en la política económica para el desarrollo. Pero, ¿cómo lograr esto último, si la relación de las fuerzas que predominan en la sociedad, y disponen de los órganos del poder social, tiene como resultante el mantenimiento de un orden estacionario?

En una sociedad ya en trance de desenvolverse, en la cual los procesos de desarrollo económico ya se abrieron paso, con los cambios sociales y políticos concomitantes, pueden presentarse también, y casi cabría decir que es normal que se presenten desequilibrios más o menos profundos, más o menos serios. Idealmente, lo racional sería que el cuadro sociopolítico, una vez plasmado en las nuevas circunstancias del desarrollo, marchara fluidamente, descansando en las fuerzas económicas en ascenso, readaptándose a ellas, renovándose y renovándolas de una manera constante. Pero en la realidad es casi seguro que ocurran rezagos, desfasamientos y hasta dislocaciones, que pueden comprometer, debilitar, interrumpir, o aun hacer volver atrás al desarrollo, al tomar cuerpo y manifestarse, con diversos grados de intensidad, nuevas contradicciones entre los órdenes económico y socio-político (englobando las fuerzas internacionales). Cómo evitar, corregir o por lo menos reducir hasta una proporción no peligrosa esos obstáculos y resistencias al desarrollo, e impedir que la sociedad caiga en una fase de estancamiento, inestabilidad o retroceso, es también uno de los desafíos importantes que tenemos hoy planteados ante nosotros en diversos paises.

\section{Algunos rasgos de la historia mexicana}

Con el propósito de afirmar estas ideas ilustrándolas con la experiencia de México, voy a intentar trazar ahora unos cuantos rasgos gruesos, que me parecen relevantes en el panorama de la historia mexicana, y sobre cuyo significado desde el punto de vista de los problemas contemporáneos del desarrollo, me parece que vale la pena meditar. 
El año de 1867 es una de las fechas clave para México. Tras la derrota de la intervención francesa, ese año quedaron definitivamente restauradas las instituciones republicanas, y se abrió el camino para el desarrollo que alcanzó el país en las décadas que siguieron. Antes, durante casi sesenta años, vivimos en una inestabilidad constante, por momentos caótica; padecimos dos violentas guerras intestinas, y por lo menos dos agresiones extranjeras, una de las cuales nos costó la mitad del territorio nacional. Esto, amén de infinidad de golpes de estado, y revueltas; demostraciones de fuerza y presiones de las potencias extranjeras, y condiciones de estancamiento, desarticulación y retroceso de la vida económica, apenas salpicado todo ello por algunos esfuerzos para dar bases democráticas a la vida del país, y liberar fuerzas que indujeran a su progreso material. Esos esfuerzos triunfaron finalmente en 1867; es la obra de Juárez, quien ocupa el lugar de honor entre los próceres mexicanos. Fue la fundación del México moderno.

Tal vez quepa en unas cuantas palabras el relato de las circunstancias que condujeron al país a los sesenta años de inestabilidad, intromisión extranjera y estancamiento, superados en 1867. Hacia los últimos años del siglo XVIII y la primera década del XIX, cuando México era todavia el Reino de la Nueva España y reconocía como su soberano al monarca español, se manifestó un temprano impulso de avance de la economía, que coincidió con el primer intento de plasmar un orden político más representativo. El auge minero en el país que era el principal productor de plata, en una época en que se intensificaba el comercio mundial, y se requerían en mayor medida los signos del cambio, siendo en esos años muy grande el prestigio del metal blanco, favoreció la expansión de algunos sectores de la actividad agrícola, y estimuló un mayor avance de las actividades manufactureras, artesanales casi todas, aunque ya algunas fabriles, si bien con las técnicas anteriores a la revolución industrial.

La corte de Madrid vivió entonces años excepcionales, en que el espíritu ilustrado de los ministerios liberales se propuso abrir cauces para un intercambio más intenso entre la metrópoli y las colonias, corrigiendo hasta cierto punto los privilegios monopólicos que lo habian limitado, y para hacer posible el florecimiento económico de las colonias. A México llegaron en ese tiempo dos o tres de los virreyes, como el segundo conde de Revillagigedo, que todavía se recuerdan entre los grandes constructores de la nación por el empeño con que se propusierón restringir la influencia de los comerciantes a quienes había favorecido el monopolio; apoyar, con lo que ahora llamaríamos medidas de fomento, el avance de la mineria, hacia la que se canalizaron fondos de las cajas del Rey, y cuya legislación se modernizó, depurándola de confusiones y trabas de raigambre medieval; corregir los obstáculos al intercambio interno, tanto los físicos mediante caminos (y entonces se construyeron o mejoraron algunos), como los derivados de localismos fiscales y barreras institucionales; proteger los precios que se pagaban a los productores del campo; impartir un mayor grado de eficiencia a la administración. Se reanudó el impulso colonizador en los territorios que hoy constituyen los estados norteamericanos fronterizos a México. Los edificios públicos, las residencias particulares y las obras con fines productivos que todavía se conservan de esa época dan una idea de la magnitud de los capitales que estaban acumulándose en el país.

Hacia esas fechas la ciudad de México era el asiento de las más doctas instituciones cientificas y culturales del Continente. Existía además 
un grupo de hombres alerta sobre el saber de su tiempo, hasta los cuales habia llegado el acervo de la ilustración europea, a enriquecer y renovar la añosa herencia del humanismo hispánico. No faltaban, por supuesto, hondos contrastes en la sociedad, ni vicios en el funcionamiento de las instituciones ni, sobre todo, resistencias a la transformación social y política para la que estaban creándose condiciones objetivas. El conflicto, que había ido configurándose lentamente en el transcurso de varios lustros, sé mostró visible y estalló en forma crítica en 1808 . La invasión napoleónica había dejado a España sin una autoridad capaz de hacerse respetar también en la América española. Un grupo de mexicanos ilustrados, que se colocó en la vanguardia del desarrollo del país en aquel momento, proyectó - apoyándose sobre todo en precedentes del derecho español - que ese vacío de autoridad se llenara mediante una junta a la que enviarian sus representantes los municipios del país, y la cual quedaría colocada al lado del virrey como depositaria de la soberanía. La moción tomó cuerpo en el ayuntamiento de la capital; la apoyaban individuos cultos del gobierno virreinal y del clero y algunos hombres prominentes de la sociedad, incluso algunos de los más ricos mineros. El propio virrey estaba de acuerdo en que se diera ese paso, sin perjuicio de los derechos del rey legítimo en España, cuando quedara éste restablecido en su trono. El virrey tenía bajo su mando un ejército. Las condiciones eran, pues, propicias para dar un paso que, en su momento, habría facilitado una transición no desquiciante del desarrollo económico y social y si favorable a él, de nuestro carácter de colonia a la categoría de nación independiente. Pero no sucedió así. La oportunidad se perdió: las nuevas fuerzas fueron aplastadas por las viejas.

Los comerciantes de la capital, apoyados por los de Veracruz, Zacatecas y otras ciudades, con los que compartian las ventajas de su predominio en los mercados internos y en el intercambio con España; una parte de los funcionarios virreinales, entre ellos los burócratas rutineros y los que alcanzaban una parte de los frutos del monopolio mercantil y del contrabando de géneros europeos, así como el tribunal eclesiástico de la inquisición y un sector del alto clero; todas estas fuerzas se concertaron con el fin de ahogar el movimiento que comenzaba. Cierta noche una banda de dependientes del comercio, armada clandestinamente por sus patronos, dirigida por uno de ellos y bendecida por sacerdotes fanáticos, irrumpió en el palacio del virrey, se apoderó de la persona de éste, que luego fue encarcelado, y abrió el camino para que se estableciera un gobierno despótico. A ello siguió el encarcelamiento de los principales campeones de las reformas, algunos de los cuales recibieron después una muerte violenta y sigilosa. Se iniciaron años de represión cruel, apoyada en tropas cada vez más numerosas que despachaba la Corte española. La independencia no pudo alcanzarse sin una guerra civil, una asoladora guerra civil que permaneció indecisa durante más de una década, hasta 1821 , y que sólo se resolvió por la vía de un compromiso, por virtud del cual quedó roto el nexo de subordinación a la metrópoli, pero el país nació debilitado y dividido, siendo parte de él, y parte muy influyente, quienes habian luchado para que no se constituyera.

Historia que nuestros historiadores cuentan con un profundo pesar, y que vemos por desgracia repetirse en este siglo en otros países. Trance en el cual se nos muestra cómo las estructuras sociales y politicas tradicionales entraron en contradicción con las fuerzas económicas nuevas, 
y con el pensamiento y las necesidades de reforma de la sociedad que el crecimiento de éstas exigía, produciéndose la consecuencia de que el país cayera, durante los 46 años que siguieron, a partir de 1821 hasta 1867, en la errática situación, adversa a todo avance, en que lo caduco no acababa de caducar y lo nuevo no acababa de imponerse.

Un sintoma histórico de las posibilidades que entrañaba el desarrollo del país, aparece, sin embargo, en esos años adversos, hacia la tercera y la cuarta década del siglo XIX, al establecerse las primeras fábricas textiles con las máquinas no demasiado tiempo antes inventadas en Inglaterra, e iniciarse el uso de los motores de vapor, ya intentado por primera vez en 1817 , en la minería y en algunas de las escasas industrias del país. Estas fábricas, como las ideas liberales, vegetaron raquíticas, plantas intoleradas aunque adheridas firmemente en un suelo yermo, mientras no viniera a aterrarlas y nutrirlas el cambio social y político indispensable, aunque aplazado por tanto tiempo. Ese cambio es el que consumó Juárez, y voy a procurar caracterizarlo en unas cuantas palabras. Con él se liquidó el orden feudal, y se abrieron las puertas para el desarrollo del capitalismo en México.

Para que la causa de la Reforma pudiera salir avante, fue necesario que un ejército popular derrotara primero al ejército profesional heredado de la colonia, incapaz de hacer la defensa del país cuando ésta había sido necesaria, y el cual formaba una casta sin principios, puesta alternativamente al servicio de todas las facciones, y de la que, sobre todo, se sujetaron los partidarios del orden antiguo, como de una tabla salvadora. Después, fue necesario que el gobierno reformista, una vez conquistado el poder, desamortizara los cuantiosos bienes que la Iglesia, casi la única institución que, si bien decadente, no se había desintegrado, tenia acumulados en sus manos, como medio y símbolo de un poder que se limitaba a subsistir, sin dar a esos bienes, propiamente, una utilidad social y un valor económico; la desamortización los sacó al tráfico normal de la propiedad, y con ello facilitó su uso provechoso como medios de producción y estimuló la circulación de la riqueza. También fue preciso que se derribaran las barreras que obstruian la libre comunicación del pensamiento y asfixiaban la vida espiritual en los ámbitos de la más intolerante ignorancia. Además, se promulgó una nueva constitución política en $\overline{18} \overline{57}$, que sancionaba los derechos de $\bar{l}$ hombre y del ciudadano, consagraba fundamentos jurídicos favorables al funcionamiento de la economía capitalista en ascenso, y organizaba al pais como una república federal, representativa y democrática. Finalmente, fue necesario defender y hacer persistir esta obra, primero contra el último esfuerzo de resistencia armada del partido derrotado, y luego contra la invasión francesa que los adalides de éste fueron a gestionar a las cortes europeas.

El México moderno data, pues, de 1867. Sobre la desamortización de los bienes del clero, que se extendió tambiẻn a los que habían pertenecido a las comunidades indígenas, dentro de formas de propiedad anteriores a la conquista española, surgió predominantemente la hacienda, definida con los rasgos de la propiedad privada, la tendencia a producir para los mercados y la reducción a peones suyos de los campesinos antes aislados dentro de sus comunidades en alta medida autosuficientes. Seguramente, el nivel de vida de las masas rurales empeoró con el cambio, pero éste, como quiera que fuese, se tradujo en un soporte para expandir el mercado interno. Los satisfactores de origen agrícola y manufacturero, que antes se procuraban los campesinos en sus parcelas co- 
munales y en sus artesanías primitivas, debía ahora proporcionarlos una producción capitalista. El proceso de desaparición de la comunidad campesina autosuficiente no fue desde luego total; aun hoy en comarcas del país todavía no bien articuladas a la economía nacional, perviven algunas, y su nivel de vida, medido en la cantidad y variedad de los satisfactores que son capaces de proporcionarse por sí propias, contrasta con las condiciones mucho menos favorables de otras comunidades ya englobadas en la economía de mercados.

La categoria del hacendado, sustentada por la del peón, fue la primera en consolidarse dentro del nuevo cuadro histórico. Por múltiples circunstancias, esta capa social fue tambièn la primera en rezagarse respecto al desarrollo de la economía, durante las décadas que siguieron, y más marcadamente de mediados de los años noventa en adelante. La abundancia de la mano de obra mal pagada permitia expandir la producción, después de que ésta se había contraído a raíz de la desamortización, sin la necesidad de que se innovaran las técnicas de trabajo, ni de que se aumentara sensiblemente la capitalización de las explotaciones. Sólo un sector de la agricultura tuvo más empuje que eso: el vinculado a los productos con demanda en el exterior, y en menor medida el que proporcionaba materias primas para las industrias nacionales. Entre las fincas productoras de bienes de consumo interno, algunas de tamaño medio, y en particular las ubicadas cerca de los mercados urbanos, lograron hasta cierto punto mejorar su eficiencia.

El cambio en la situación del campo, al penetrar a éste las fuerzas de la economía de cambio, aunque matizadas y constreñidas por los restos del feudalismo señorial, ayudó a los cambios que comenzaron a ocurrir en las ciudades. Algunas de éstas eran asiento de actividades manufactureras de cierta cuantía, en trance algunas de ser fabriles, y artesanales las más, y cuyo crecimiento registra ya un impulso perceptible desde comienzos de los años setenta. El mercado urbano fue extendiéndose hasta ámbitos económicos mayores, y los-capitales mercantiles que comenzaban a prosperar fueron encontrando una esfera provechosa en la actividad manufacturera. Las dificultades para la comunicación con el exterior y entre los distintos puntos del país habían entorpecido el crecimiento de los mercados, pero también habian significado una protección frente a la competencia extranjera. Los hombres de la Reforma se propusieron acabar con el aislamiento geográfico, y al mismo tiempo, en el punto concreto de la protección arancelaria al desarrollo fabril, admitieron apartarse del liberalismo que profesaban, instados también a ello por las necesidades fiscales. La fábrica mexicana de los años setenta y ochenta creció despacio, a base de aplicar sobre todo cantidades crecientes de mano de obra a una capacidad instalada que aumentaba poco. Después, su expansión se aceleró gracias a los nuevos capitales formados durante el proceso, y al empleo de recursos del exterior, que comenzaron a invertirse en este campo de nuestra economía. Al lado de la industria moderna, la vieja artesanía zozobró, aunque no totalmente ni en todos los sectores de la producción, y una buena parte de los artesanos se hallaron convertidos un buen día en proletariado urbano. Aun así, la cuantía de la mano de obra artesanal, lo especializado, localizado o restringido de ciertas demandas, o la peculiar estructura de la producción, con pocos bienes de capital, permitió que en muchos casos la artesanía subsistiera al lado del moderno aparato industrial, haciéndose fuerte sólo a base de la increíble privación del artesano, operando con costosísimos fondos de trabajo proporcionados por el comercio in- 
termediario, como todavía ocurre hoy en tantas ramas de la industria mexicana. Como quiera que haya sido, surgió una amplia estructura industrial, primero en las ramas de bienes de consumo (alimentos y bebidas, textil, tabaco, cuero y otras) y por lo general un poco después en las de bienes de producción (papel, productos químicos básicos, explosivos, vidrio, cemento, industrias mecánicas, y finalmente la siderurgia). Hacia 1910, México era en la América Latina el país más industrializado.

Al panorama que presentaban las fuerzas internas del desarrollo, llegaron a sumarse con una participación creciente desde los años setenta, las fuerzas del capitalismo internacional de la época. Las materias primas agrícolas y mineras que el país podía exportar atrajeron grandes inversiones de capital extranjero, principalmente europeo, aunque también y en forma cada vez mayor, norteamericano. Estos recursos privados externos encontraron una conveniente colocación en la minería, la cual absorbió pronto las nuevas técnicas tanto extractivas como metalúrgicas, y salió de su tradicional especialización en los metales preciosos, al lado de los cuales aparecieron, con importancia significativa, el cobre, el plomo, el antimonio, el zinc y otros minerales y metales industriales, cuya demanda era altamente dinámica en el extranjero. A este campo vino a sumarse desde comienzos del presente siglo el petróleo, cuya explotación quedó repartida entre los ingleses y los norteamericanos. La presencia del capital extranjero fue también decisiva para la creación de la red ferrocarrilera, respecto de la cual, y pese a su trascendente importancia para el avance del país, el gobierno y los particulares mexicanos sólo habian conseguido débiles principios.

La expansión capitalista en las actividades primarias y secundarias se reflejó también en las terciarias. El capital mercantil conservó su importancia tradicional en campos como una parte de la agricultura y en las artesanías en que la debilidad relativa de los productores los colocaba a merced del dinero caro y especulativo. Por otra parte, el capital mercantíl se vio estimulado por la expansión de las nuevas industrias, los servicios y el comercio exterior, y acabó por crearse un sistema bancario. El sistema monetario fue penetrando a todos los territorios que se ganaban para el intercambio. En una palabra, con sectores rezagados, obstáculos y fricciones, el desarrollo económico acabó por abarcar al conjunto de la economía nacional. Ese impulso.llegó a su fase culminante al mediar la década de los noventa del siglo XIX y tuvo un alto brusco en 1910, en que México se precipitó otra vez en una fase de convulsiones revolucionarias. A fin de dar aunque sea un boceto de las razones por las cuales ocurrió en nuestra historia este percance, que en 1867 se hubiera antojado improbable en, la más alta medida, es indispensable examinar algunos aspectos del comportamiento de las estructuras políticas y sociales del país durante ese periodo del desarrollo económico. Juárez pensó en una República en la cual la magistratura de Presidente tuviera el contrapeso y la colaboración de un Congreso eficaz. En éste, hallarian una expresión armónica, pero efectiva, los particularismos regionales, las corrientes de la opinión, las diversas fuerzas operantes del pais, cuya actuación tendría como resultado la de controlar constitucionalmente las acciones del primer magistrado, y al mismo tiempo estimularlas y hacerlas más poderosas en la gestión de los negocios públicos.

Porfirio Díaz inició con su dictadura, emanada de un movimiento militar, un estilo de gobierno vitalicio que depositó en su persona, y en 
las de sús más inmediatos colaboradores, toda la suma del poder del Estado, sin que faltara el requisito puramente ceremonial de las elecciones, ni estuvieran ausentes, aunque sin autoridad, los otros órganos constitucionales que deberían compartirla. Se requería, desde luego, rigor para evitar el rebrote de los vestigios de la anarquía entronizada por tantos años de luchas. Hacía falta un gobierno que manifestara fuerza y estabilidad.

Pero Díaz, que durante muchos años llegó a contar incluso con la adhesión del pais, llevó esta necesidad hasta el extremo de sustituir el diálogo entre gobernantes y gobernados por la obligada aceptación de las verdades oficiales como verdades auténticas, $y$ al pleno apagamiento de la crítica. Las consecuencias de este vicio fueron acentuándose a medida que el régimen perduraba. Por lo demás, y durante un largo trecho de su vida, el gobierno participó, alimentándolo y fortaleciéndolo incluso, del impulso que tenian las fuerzas liberadas por la reforma. La obra de la dictadura, variada y compleja, favoreció el desarrollo de la estructura económica, incluso con medidas de notable visión y eficiencia. Los porifiristas crearon un clima favorable par la inversión de capitales nacionales y extranjeros en las diversas ramas de la economía, y para el florecimiento del comercio exterior; se esforzaron por suprimir las barreras al intercambio interno (para lo cual, entre otras cosas, hicieron desaparecer las aduanas interiores, que databan de la época anterior a la independencia y que la Constitución de 1857 había.abolido); emprendieron grandes obras públicas con fines de fomento económico, urbano y sanitario-asistencial; dieron aliento al progreso de las instituciones culturales y científicas, restituyendo algunas de ellas al alto nivel que habian alcanzado en otras etapas, y en general manejaron con destreza el instrumental de que disponía, el gobierno en la época para impulsar el avance del país. Son, por ejemplo, muy brillantes las páginas de la historia financiera mexicana que refieren el manejo que supo hacer el gobierno del crédito exterior para sanear la cuenta pública y acrecentar su capacidad constructora. También es relevante el episodio de la compra por el gobierno de la mayoría de las empresas ferrocarrileras del país, para evitar que éstas se consolidaran bajo el control de un monopolio extranjero.

Sin embargo, el rezago en la estructura social; cada vez más marcada a medida que se acercaba a su término aquella dictadura de treinta y tres años, se reflejó en el anquilosamiento de la estructura política. El gran poder de los hacendados en el gobierno y sobre el gobierno obstruyó o impidió del todo que éste se preocupara por la suerte de los trabajadores del campo, cuya participación activa en la vida del país era indispensable estimular, y cuyo grado de bienestar era necesario promover, si se aspiraba a democratizar las instituciones públicas y a abonar el terreno de que se alimentase el desarrollo, con un mercado interno vigoroso. Las ideas de reforma agraria llegaron tarde, preconizadas por intelectuales a los que de momento no se escuchó, y no lograron tomar cuerpo en una fuerza, dentro de las propias instituciones, que las objetivara como una necesidad. Ante el naciente proletariado, la actitud del régimen se cifró en el más ortodoxo liberalismo; los salarios, y en general las condiciones de trabajo debían quedar confiados a las fuerzas del mercado. Se pensaba que interferir en la dinámica de éstas era contrario a las leyes de la economía. Las ideas sindicalistas tampoco encontraron un camino que las hiciera plenamente conscientes y dotadas de un peso específico en los conciliábulos de los gobernantes. En 
general, la estructura política tendió a replegarse hacia las bases de una oligarquía resistente al cambio.

Los impulsos independientes, la crítica, los afanes innovadores quedaban ahogados en un estado de cosas encarnado por personas, muchas de las cuales, muy humanamente, lo consideraban perfecto. Los síntomas de malestar comenzaron a ser claros hacia el cambio del siglo, cuando la nueva industria entró de pronto a una fase en que se le acumulaban inventarios, sin salidas en los mercados, y caía en una verdadera crisis de sobreproducción, que se reflejaba en las demás esferas de la vida económica. Las inquietudes intelectuales, el deseo de conocer los fenómenos que afectaban al país, y de evitar que éste llegara a caer en un colapso, germinan cada vez más desde entonces, y dejan libros, conferencias, ensayos, artículos y otros materiales, que ahora miramos como precursores de la revolución de 1910 , pero que en no pocos casos sobresalientes - y es muy notable el de Luis Cabrera-, sus autores hicieron pensando precisamente en cómo evitarla. La nueva crisis de los años de 1907 y 1908 apareció vinculada con una contracción de la demanda externa y baja en los precios internacionales de las materias primas que exportábamos; por primera vez, de una manera vigorosa y clara, sentimos el efecto de una relaćión de precios de intercambio desfavorable con dificultades en la balanza de pagos, acentuadas por las crecientes remesas de dividendos de las inversiones extranjeras, fenómenos que tantas veces han retornado después a nuestra experiencia. Desde el punto de vista puramente económico, la falla del sector externo constituyó un grave traspié, al acentuar las condiciones internas desfavorables, resentidas sobre todo por el creciente debilitamiento del mercado a que concurrían las actividades productoras básicas y por los tensos desajustes entre los sectores, particularmente entre el industrial y el agrícola. Los síntomas agudos de la crisis económica antecedieron en un par de años o tres a la crisis política, años durante los cuales los representantes de las tendencias nuevas, que antes no habian logrado articularse, entraron definitivamente en la palestra, teniendo el trasfondo de un malestar social que en parte era crónico en las masas, y en parte se acentuó con el efecto de la desocupación, la baja del ingreso real, y los métodos de mano de hierro que la dictadura empleó para reprimir las primeras huelgas y otras manifestaciones de la inconformidad de los sectores populares por la suerte que estaba tocándoles, y los cuales acabaron por sentir, de esta indubitable manera, que el poder en el que habian creido descubrir antes un signo tutorial o paternalista que les inspiraba respeto, no era de ellos, sino contrario a ellos. El movimiento que surgió postulaba primero una renovación política, más que un cambio en la estructura social; tal vez éste habría venido gradualmente de haberse instaurado el juego democrático, pèro la manera en que se aferraron a la dictadura las fuerzas que la habían hecho posible, condujo inevitablemente al choque. El periodo revolucionario fue hondamente destructivo, no sólo de vidas, muchas y muy valiosas, y de bienes materiales considerables, sino también de organización. Más tarde, en muchos casos fue necesario recomenzar otra vez desde el principio. La fase violenta del conflicto se prolongó por lo menos hasta 1921; el restablecimiento de las instituciones de gobierno conforme a las nuevas circunstancias tardó hasta 1934 o 1935, y sólo a partir de estos últimos años, o un poco después, reanudó el país la marcha del desarrollo interrumpido en 1910.

Trataré ahora de esquematizar en unas cuantas líneas el sentido más 
general de los cambios que sólo pudieron abrirse paso por una vía revolucionaria, en la cual, nuevamente, un ejército popular tuvo que destruir en cruentas batallas a un ejército profesional. Se aplicó una reforma agraria que desmembró la propiedad de los hacendados y liquidó para siempre la influencia social y política de éstos. Se abrió campo para que creciera la clase media, propietaria o dedicada a los servicios, entre ellos el de la administración pública. Se establecieron cauces legales para la acción del sindicalismo y para normar las relaciones obreropatronales. Se establecieron limites a la acción económica del capitalismo extranjero en el país y, en general, a la propiedad privada. Se atribuyeron al Estado funciones de gran amplitud como promotor de la economía. Todo esto quedó consagrado en la Constitución de 1917 que, por lo demás, reprodujo con pocas alteraciones sustanciales el mismo sistema de la Constitución de 1857. Poco a poco, y con varias alternativas, entre ellas nuevas intromisiones o intentos de intromisión del extranjero, estos designios fueron cobrando cuerpo en la realidad del país. Mencionaré en especial la expropiación petrolera, en 1938, episodio final de la lucha entre las compañías extranjeras y el gobierno mexicano, en torno a si aquéllas lograban eludir o no la autoridad de éste, y cumplian o no con las leyes del país.

Favorecido por estas reformas y conquistas, el desarrollo económico del pais pudo, por fin, reanudarse a partir de fines de la década de los años treinta. El gobierno contribuyó decisivamente a ello con su programa de grandes obras infraestructurales en materia de transportes, plantas generadoras de electricidad y otras, que se tradujeron en importantes economías externas ventajosas para expandir los diversos sectores de la producción. El propio gobierno tomó una participación aún mayor en la vida económica, creando organismos públicos para financiar y fomentar la agricultura, la industria, los transportes y otras ramas, y tomando directamente a su cargo algunas empresas industriales o de servicios que era indispensable estimular, sin aguardar a que los particulares las desarrollaran. Por otra parte, el sector público dio un: fuerte impulso a la educación, los servicios sanitarios y asistenciales y la seguridad social, todo lo cual se ha traducido en una disminución considerable del analfabetismo, la mortalidad y el desamparo. Al lado de la inversión pública, la privada ha crecido también, incluso en más fuerte medida.

Durante los años de la segunda Guerra Mundial, y hasta mediados de la década de los cincuenta, la demanda externa para los productos mexicanos de exportación constituyó un fuerte aliciente para el desarrollo económico. Este aliciente se ha debilitado sensiblemente en los últimos años, por la atonía en que han caído los mercados internacionales, y ahora la economía del país tiende a encontrar un estímulo más amplio en la demanda interna, sin que se prescinda, por supuesto, de la externa, de la que forma parte la afluencia turística al país, y entre la que despunta como una perspectiva alentadora la integración del mercado común latinoamericano. En muchos casos, ha sido y sigue siendo posible desarrollar nuevas ramas de la producción que sustituyan importaciones.

De los logros alcanzados por el desarrollo económico de-México durante los últimos veinte años dan una idea, entre otros, los datos que siguen. Entre 1940 y 1960, los principales sectores de la economía del país, salvo el minero, expandieron su producción entre tres y cuatro veces. El ingreso real del país aumentó a una tasa media del $6 \%$ anual, 
frente a un aumento de la población del $3 \%$, lo que indica un ascenso sensible en el ingreso medio por habitante. Del total de personas en edad de trabajar, la proporción que se encuentra económicamente activa subió de un poco más del $53 \%$ en 1940 a más del $62 \%$ en 1960 . La parte de la población activa dedicada a las actividades agropecuarias bajó entre esos dos años de casi el $64 \%$ a un poco más del $50 \%$, mientras creció correlativamente la consagrada a la industria, el transporte, el comercio, los servicios y las labores gubernamentales. En los veinte años se ha cuadruplicado la capacidad instalada para generar energía eléctrica; en los últimos quince años, la producción de acero se ha quintuplicado; la industria química, la mecánica y otras han enriquecido la gama de sus productos y aumentado también en forma notable su capacidad de producción. Entre otras cosas, avanżamos ahora hacia la fabricación de vehículos.

Está a la vista de todos el progreso material logrado por México, un progreso que se corresponde con las nuevas condiciones, en las que hay mejores niveles en los planos cultural, técnico y humano. Nuestro deseo, como es natural, consiste en poder mantener ese proceso, en términos progresivamente más favorables. Algunos observadores y estudiosos de otros países se sienten inclinados a pensar que el caso mexicano es digno de emulación en estos años en que, me atrevo a decir que por ventura, el problema del subdesarrollo está planteado en el mundo en términos que no admiten aplazamiento. Que aquí logremos seguir adelante depende de la manera en que sepamos hacer frente a ciertas situaciones de desajuste que comienzan a cobrar más relieve entre nosotros, y de.las cuales quisiera señalar por lo menos algunos aspectos.

\section{Algunos problemas mexicanos contemporáneos}

Por varios motivos, ajenos unos a lo que pudiera considerarse efectos previsibles y evitables de la politica económica, y asociados otros con las tendencias y las omisiones de esa política, hemos caído en una distribución del ingreso notablemente desfavorable por sus incidencias e implicaciones actuales y potenciales sobre la vida social y sobre el desarrollo económico del país. Sabemos, por datos relativos a 1957, que en un extremo de la escala social, el $2.3 \%$ de las familias disfrutan el $24 \%$ del ingreso personal disponible, y en el otro, al $46 \%$ de las familias les toca sólo el $14 \%$ del ingreso. Agregando al grupo más alto que le sigue en prosperidad, resulta que al $16 \%$ de las familias les toca algo más del $56 \%$ del ingreso, y que con el otro $44 \%$ de éste debe arreglárselas nada menos que el $84 \%$ restante de las familias. Son obvias las implicaciones de esta mala distribución del ingreso que, por cierto, parece llevar trazas de empeorar, en cuanto a la posibilidad de polarizar hacia campos opuestos, en vez de armonizar, las fuerzas que entrañan los diferentes estratos de la sociedad, sobre todo los menos favorecidos. Desde el punto de vista económico, la pobreza de una gran mayoria mina las bases del mercado interno, de cuyo crecimiento depende la expansión de la industria de bienes de consumo, estratégica para los otros aspectos del desarrollo. En la otra cara de la medalla, la riqueza concentrada en las capas de ingresos mejores - no todas las cuales están formadas de empresarios y capitalistas constructivos y progresistasdistrae hacia fines improductivos, e ircluso irracionales, como el de mantener ociosos fondos en el extranjero, una parte grande de los escasos recursos de la sociedad. En este sentido, va evidenciándose un nue- 
vo desfasamiento de la estructura social respecto a la estructura económica del país. Se requeriría que los grupos a cuyas manos va a parar una buena parte del excedente de la economía lo encauzara hacia las diversas finalidades que reclama el crecimiento de ésta, en vez de absorberlo de una manera parasitaria.

En contraste con ese fenómeno, las condiciones fiscales del gobierno carecen de toda la robustez deseable. En México el Estado absorbe sólo alrededor del $10 \%$ del producto nacional bruto, proporción que se compara muy bien desfavorablemente, por lo baja, con la de muchos otros países. Si bien este dato hace que resalte aún más la magnitud de la obra material consumada por el gobierno, desde otro punto de vista constituye una de las explicaciones de que el ingreso esté mal repartido, y de que sean insuficientes los recursos para afrontar la cuenta corriente del sector público, incluido el pago al personal burocrático, y para soportar el ritmo de inversiones gubernativas que se requiere para alimentar el desarrollo. Y esto último aun considerando la magnitud del financiamiento externo que podemos obtener prudentemente de acuerdo con nuestra capacidad para endeudarnos. Un estancamiento del desarrollo que se asociara con la falta de ímpetu del sector público como promotor e inversionista constituiría un síntoma de que los términos de la estructura social, reflejándose en la estructura política, estaban determinando el rezago de ésta respecto de las marcas mínimas que reclaman la estabilidad y el dinamismo de la estructura económica.

Puede comprobarse la validez de la observación anterior mirando cómo el sector agropecuario de nuestra economía presenta manifestaciones de retraso y falta de equilibrio interno respecto a los demás sectores. La elevada tasa de crecimiento demográfico somete a especial presión a los recursos de que se sustenta la agricultura y lanza constantemente a los mercados de trabajo una caudalosa corriente de mano de obra no calificada. Pero el aumento de la población no puede considerarse como el origen de un mal, sino como un factor al que habrá de adecuarse la movilización de los medios con que cuenta la economía, dando más pujanza al propio sector agropecuario, a base de corregir la subocupación y la baja productividad, y haciendo más ágil todavía el ritmo de la industrialización, la cual habrá de proliferar los empleos. La agricultura mexicana ha mejorado en amplia medida el nivel global de su capitalización y de su eficiencia productiva, pero la rama fundamental de ella, o sea la que cosecha artículos de consumo para el interior del país, resiente las consecuencias de varias dificultades no superadas, que por cierto aparecen también hasta cierto punto en las demás ramas del sector agropecuario. En esencia, esas dificultades tienen que ver con varios géneros de factores. Uno de ellos es el fuerte retraso de la inversión pública, $y$ en sentido más amplio, del esfuerzo del gobierno en lo que toca a la conservación productiva y al mejor aprovechamiento de los recursos, y a promover la organización y la técnica de las explotaciones del campo. La principal realización, de efectos ciertamente trascendentes, aunque como es obvio un tanto localizados, está lograda en las grandes obras de riego. Hay mucho por hacer en cuanto a obras de riego menores, aunque más repartidas geográficamente; a trabajos de defensa de los suelos y a otras direcciones de la ingeniería agrícola, aparte de la formación de servicios extensionistas amplios y eficaces que aceleren la asimilación por nuestros agricultores de técnicas y medios de trabajo más modernos. Otra vertiente de los problemas que afectan a la economía agrícola del país radica en la precaria posición 
que los productores, muchos de ellos minifundistas aún no integrados dentro de unidades mayores de escala costeable, tienen en los mercados agrícolas locales y regionales, dominados por un capitalismo intermediario que deteriora la distribución del ingreso generado en el campo, e impide la formación de capital en una extensa parte de todo el sector agrícola. Sería injusto desconocer que en todos estos órdenes de problemas el gobierno, y a veces más tímidamente, los particulares, han realizado intentos útiles y han emprendido programas bien dirigidos, pero no hay duda de que lo que falta por hacer es mucho y urgente. La tarea no es desproporcionada a nuestros medios; no toda ella es de dinero, y quizá, cuantitativa y cualitativamente, sea más lo que puede lograrse a base de una mejor organización y coordinación del esfuerzo público y de éste con los agricultores. Evidentemente, el deterioro del nivel de vida de la población campesina, relacionado con el uso ineficiente y empobrecedor de los recursos, con la mala repartición del ingreso generado en la agricultura, y con las raquíticas oportunidades ocupacionales para los brazos rurales excedentes, implica circunstancias desfavorables, que se acentúan, en la estructura social del país. La agudización de esas circunstancias indicaría también una menor capacidad de la estructura política del país, y de sus mecanismos correctores y promotores, para responder a las exigencias del desarrollo económico.

Ya apuntaba hace un momento que desde el punto de vista de los empleos nuevos que se requiere asegurar para la creciente población del país, nuestro desarrollo industrial, aun siendo rápido, seguramente no ha sido satisfactorio. Desde ese punto de vista, las industrias se encuentran con las limitaciones de un mercado interno que requiere una pujanza creciente que no está teniendo, y además algunas de ellas tropiezan todavia con la competencia artesanal, desarticulada y múltiple, que puede sostenerse por la abundancia de brazos a los que no les queda otro remedio que aceptar el nivel minimo de subsistencia, a merced de los intermediarios que les refaccionan o les compran su producción. Un aumento sensible en el ingreso de la población rural y, en general, un progreso firme de la agricultura haría mejorar las perspectivas de la industria, no sólo en lo tocante a bienes de consumo, sino también en cuanto a producir implementos, maquinaria e instalaciones para el cultivo y beneficio de los productos del campo. La expansión industrial tendería a lograr una mayor ocupación de los pobladores en edad de trabajar, más convenientemente distribuidos por sectores de actividad, y aliviaría a los mercados de trabajo de la actual presión que ejerce sobre ellos la mano de obra disponible, lo cual tiene consecuencias desfavorables para los intereses de las clases trabajadores y para la estructura política del país. En otro aspecto, el avance de muchas ramas industriales permitiría que el pais prosiguiera sustituyendo importaciones, y liberando con ello recursos para adquirir en el exterior bienes que no produce, o cuya producción interna es insuficiente, y que son importantes para cubrir diversas necesidades de la economía. Hay que señalar que la integración de la estructura industrial del país, logrando empalmar adecuadamente unas ramas con otras, y evitando vacíos, desarticulaciones y expansiones no proporcionadas, requiere una complementación de las inversiones públicas y privadas. Ahora bien, afectan dañosamente a las perspectivas de una más intensa industrialización la debilidad del sector público como inversionista y la sangría que padecen las energías del sector privado y de la economia nacional en su conjunto, por la parte de los recursos acumulados por él que se sustraen 
hacia fines no productivos. He aquí otro campo en el que la falta de vigor y las ineficiencias del sector público, aquí en su carácter de promotor, planeador y orientador del avance fabril del país, estarían indicando objetivamente un deterioro de la estructura politica frente a las exigencias de la estructura económica del país.

Llego así al término de esta exploración, que tal vez se haya prolongado demasiado por el afán de proporcionar un panorama y al mismo tiempo de reconocer recodos del camino y examinar accidentes de la marcha. Y llego sin poder dar propiamente una respuesta a la pregunta con que inicié mi exposición. Pero creo haber aportado, como lo anunciaba en un principio, algunos elementos de juicio para encontrar esa respuesta. Evidentemente hay ciertos desajustes entre la estructura social y política del país y las exigencias del crecimiento económico. En una palabra, la distribución muy desfavorable del ingreso nacional; el empleo parasitario de una buena porción de los excedentes generados por la economía; la debilidad fiscal del gobierno, que compromete su capacidad cớmo factor clave del desarrollo; el profundo retraso en la agricultura y la pérdida de aliento de la industrialización indican, objetivamente, que los términos de la estructura social y política del país tienden a alejarse de lo que sería deseable para un crecimiento económico serio y firme. Evidentemente, también, esos desajustes pueden ser corregidos por la vía de una planeación que haga el Estado en su política económica, apoyándose en el empleo serio y empeñoso de la técnica, y con el estímulo de un rejuego democrático de las fuerzas del país, que armonice los objetivos a lograr y equilibre y dé mayor vigor a la acción del Estado. Cómo lograr esa revitalización democrática de las instituciones constituye un punto que habrá de figurar entre las preocupaciones centrales de quienes desean sinceramente que el progreso nacional no se detenga. Por otra parte, los procesos históricos, y más en esta época que nos ha tocado vivir, son altamente dinámicos y frente a ellos no queda lugar para la profecía o las actitudes personales, o campo para convertirlos en materia de banderías partidarias. Sólo cabe frente a ellos el comportamiento elevadamente político, de sumar el esfuerzo de cada uno al hondo esfuerzo social que se requiere para determinar la naturaleza de los problemas y encontrarles y darles una salida racional y factible históricamente. Quisiera afirmar, por último, que la sociedad mexicana encierra experiencias, y cuenta con reservas de energia material, moral e intelectual para hacer una planeación económica, de ninguna manera perfecta, pero sí mínimamente eficiente, de lo que con seguridad depende que nuestro porvenir no vuelva a ser una tragedia. 